\title{
OÚRICUR'
}

\section{ATIVIDADE REPELENTE E AÇÃO ANTIMICROBIANA DE PEÇONHA DE Dinoponera}

\author{
quadriceps (Hymenoptera: Formicidae)
}

\section{Erica dos Santos ARAUJO ${ }^{1 *}$; Edson de Jesus MARQUES ${ }^{2}$; Jaqueline dos Santos CARDOSO; Eltamara Souza da CONCEIÇÃO²}

\begin{abstract}
${ }^{1}$ Doutoranda do Programa de Pós-graduação em Genética e Biologia Molecular, Universidade Estadual de Santa Cruz, Ilhéus-BA, Brasil. *Autor correspondente. E-mail: eraraujo@hotmail.com.br; 2Departamento de Ciências Exatas e da Terra, Universidade do Estado da Bahia, Campus II, AlagoinhasBA, Brasil;

3'Laboratório de Estudo Animal, Universidade do Estado da Bahia, Campus IV, Caetité-BA, Brasil.
\end{abstract} Recebido: 20.09.2019 Aceito: 30.05.2020

Resumo: A peçonha de formigas tem sido investigada por ser uma potencial fonte de peptídeos com alta atividade antimicrobiana. O que a torna uma fonte atrativa para o isolamento de novos compostos químicos para o combate aos microrganismos resistentes ou como repelente contra outras formigas, principalmente as consideradas pragas. O objetivo deste estudo foi avaliar se a peçonha de Dinoponera quadriceps possui atividade repelente contra a formiga cortadeira Atta sexdens e se também possui ação antimicrobiana. Colônias de $D$. quadriceps foram coletadas por meio da escavação dos ninhos e captura manual dos indivíduos no município de Esplanada/BA. Os espécimes coletados foram mantidos em ninhos artificiais no Museu de Zoologia da UNEB, Campus II - Alagoinhas/BA. Foram utilizadas duas técnicas de extração da peçonha. Na primeira, extraiuse a peçonha de cinco formigas utilizando-se um microtubo graduado. Na segunda, a extração consistiu na imobilização de um indivíduo com pinça entomológica e o ferrão introduzido em um tubo capilar. Este tubo foi colocado em contato com água destilada e posteriormente a substância extraída foi impregnada em papel filtro. Os bioensaios foram realizados em béqueres de $500 \mathrm{~mL}$. Ambas as técnicas de extração da peçonha foram repetidas 10 vezes, para cada bioensaio, e as 10 operárias de $A$. sexdens foram coletadas individualmente para a realização de cada experimento e descartadas em seguida. Posteriormente, foi avaliado o comportamento das operárias. Para avaliação da atividade antimicrobiana foi utilizado o método da difusão em discos, com base no halo de inibição contra as bactérias Staphylococcus aureus, Micrococcus luteus, Bacillus subtilis, Escherichia coli e Pseudomonas aeruginosa. Os testes com a peçonha de D. quadríceps, não apresentaram ação repelente e nem atividade antibacteriana.

Palavras-chave: Ponerinae, Atta sexdens, Bioinseticida.

\section{REPELLENT AND ANTIMICROBIAL ACTIVITY of the Dinoponera quadriceps VENOM (Hymenoptera: Formicidae)}

\begin{abstract}
Ant venom has been investigated as a potential source of peptides with high antimicrobial activity. What makes it an attractive source for the isolation of new chemical compounds to resistant microorganisms or as a repellent against other ants, especially those considered pests. The aim of this study was to evaluate whether the venom of Dinoponera quadriceps has repellent activity against the leaf-cutting ant Atta sexdens and whether it also has antimicrobial action. $D$. quadriceps colony were collected by excavating the nests and manual capture of individuals in the municipality of Esplanada/BA. The collected specimens were kept in artificial nests in the Museu de Zoologia UNEB, Campus II - Alagoinhas/BA. Two venom extraction techniques were used. In the first, the venom was extracted from five ants using a graduated microtube. In the second, the extraction consisted of immobilizing an individual with entomological forceps and the stinger inserted in a
\end{abstract}


capillary tube. This tube was placed in contact with distilled water and the extracted substance was impregnated in filter paper. The bioassays were carried out in $500 \mathrm{~mL}$ beakers, 10 for each of the two techniques. Both venom extraction techniques were repeated 10 times, for each bioassay, as well as the 10 workers of $A$. sexdens were collected individually for each experiment and discarded later. Subsequently, the workers' behavior was assessed. For the evaluation of antimicrobial activity, the disk diffusion method was used, based on the inhibition halo against Staphylococcus aureus, Micrococcus luteus, Bacillus subtilis, Escherichia coli and Pseudomonas aeruginosa bacteria. The tests did not reveal any repellent action or antibacterial activity for the $D$. quadriceps venom.

Keywords: Ponerinae, Atta sexdens, Bioinsecticide.

\section{ACTIVIDAD REPELENTE Y ACCIÓN ANTIMICROBIANA DEL VENENO DE Dinoponera quadriceps (Hymenoptera: Formicidae)}

Resumen: El veneno de hormiga ha sido investigado como una fuente potencial de péptidos con alta actividad antimicrobiana. Siendo una fuente probable para el aislamiento de nuevos compuestos químicos para combatir microorganismos resistentes o como repelente contra otras hormigas, especialmente aquellas consideradas plagas. El objetivo de este estudio fue evaluar si el veneno del Dinoponera quadriceps tiene actividad repelente contra la hormiga cortadora Atta sexdens y si también tiene acción antimicrobiana. Fueron recogido colonias de $D$. quadriceps mediante la excavación de nidos y la captura manual de individuos en el municipio de Esplanada/BA. Las muestras recolectadas se mantuvieron en nidos artificiales en el Museu de Zoologia UNEB, Campus II - Alagoinhas/BA. Se utilizaron dos técnicas de extracción de veneno. En el primero, se extrajo el veneno de cinco hormigas usando un microtubo graduado. En el segundo, la extracción consistió en inmovilizar a un individuo con pinzas entomológicas y el aguijón insertado en un tubo capilar. Este tubo se puso en contacto con agua destilada y luego la sustancia extraída se impregnó en papel de filtro. Los bioensayos se realizaron en vasos de precipitados de $500 \mathrm{ml}$. Ambas técnicas de extracción de veneno se repitieron 10 veces, para cada bioensayo, y los 10 trabajadores de $A$. sexdens se recogieron individualmente para cada experimento y se descartaron después. Posteriormente, se evaluó el comportamiento de los trabajadores. Para la evaluación de la actividad antimicrobiana, se utilizó el método de difusión en disco, basado en el halo de inhibición contra Staphylococcus aureus, Micrococcus luteus, Bacillus subtilis, Escherichia coli y Pseudomonas aeruginosa. Las pruebas no revelaron ninguna acción repelente o actividad antibacteriana para el veneno de $D$. quadriceps.

Palabras clave: Ponerinae; Atta sexdens; Bioinsecticide.

\section{INTRODUÇÃO}

A ordem Hymenoptera é constituída por mais de 100 mil espécies e compreende abelhas, vespas e formigas (Steen et al., 2005). Muitos membros desta ordem apresentam um ovipositor modificado em ferrão funcional localizado na base terminal do abdômen, o qual é utilizado como estrutura ofensiva injetável ou defensiva (tóxicos e/ou repelente), e na comunicação social para alarme ou recrutamento (Schmidt, 1986; Charpin, 1994; Abdalla et al., 2001).

Na família Formicidae, as subfamílias Formicinae, Dolichoderinae, Aneuretinae e Dorylinae não possuem ferrão ativo e liberam suas toxinas através da pulverização ou por um ferrão residual, mas não funcional (Brady et al., 2006). As demais subfamílias utilizam um ferrão funcional, formado por duas glândulas associadas: a de peçonha e a de Dufour (Abdalla et al., 2001).

Apesar do notório potencial que os peptídeos da peçonha de formigas apresentam, o número de investigações e a caracterização proteômica ainda são escassos, se comparados ao de vespas

Revista Ouricuri, Juazeiro, Bahia, v.9, n.2. p.035-046. jul./dez., 2019.

http://www.revistas.uneb.br/index.php/ouricuri | ISSN 2317-0131 
e abelhas (Steen et al., 2005). O gênero Dinoponera é um dos mais investigados quanto a atividade biológica da peçonha, com estudos sobre atividade antinociceptiva (Souza et al., 2012) e caracterização e diversidade de toxinas (Johnson et al., 2010).

A atividade repelente e tóxica da peçonha de formigas é conhecida para Neoponera goeldii Forel, 1912 (Orivel et al., 2001), Nylanderia fulva Mayr, 1862 (Lai et al., 2015) e Crematogaster scutellaris Olivier, 1792 (Marlier et al., 2004). Isso levanta questionamentos sobre a capacidade da peçonha de outras espécies de formigas também possuírem atividade repelente contra outros insetos e até mesmo outras formigas, consideradas pragas.

Dentre as formigas pragas, as cortadeiras são tidas como uma das principais pragas agrícolas no Brasil, sendo os gêneros Atta (saúvas) e Acromyrmex Mayr, 1865 (quenquéns), os de maior importância econômica, devido aos grandes prejuízos à agrossilvicultura e às pastagens naturais e cultivadas (Della-Lucia e Souza, 2011).

Apesar dos diversos esforços para encontrar métodos sustentáveis de manejo das formigas cortadeiras (Cintra et al., 2005; Oliveira et al., 2006), a única tecnologia empregada em larga escala disponível é a baseada no controle químico. Porém, a alta complexidade comportamental das cortadeiras, sua capacidade de aprendizagem e identificação de substâncias tóxicas para o seu fungo simbionte ou para as operárias, tornam esse método de controle pouco eficaz (Marinho et al., 2006).

Portanto, avaliações para possíveis indicações do uso de bioinseticidas são altamente relevantes como meio alternativo ao controle químico, tanto pelos motivos acima citados, assim como também pela perspectiva de redução dos impactos ambientais provocados pelo uso de defensivos agrícolas.

Atualmente, muitos dos medicamentos utilizados foram produzidos a partir de compostos bioativos derivados de plantas e animais (Viegas et al., 2006). Os artrópodes ainda são considerados uma fonte importante de toxinas (Santos et al., 2011), e uma melhor compreensão da atividade biológica e mecanismo de ação dessas substâncias, permitirá o desenvolvimento de drogas para o combate a diversas doenças (Saidemberg et al., 2011). Assim, estudos que investiguem a atividade biológica da peçonha de formigas auxiliam pesquisas mais detalhadas quanto a identificação de compostos de interesse (Vaso et al., 2011), descoberta de estruturas moleculares (Arcuri et al., 2011) e síntese de moléculas para aplicações na indústria química e farmacêutica.

Nossa hipótese é que a peçonha de Dinoponera quadriceps Santschi, 1921, possua atividade repelente contra formigas cortadeiras, e atividade antimicrobiana contra bactérias grampositivas e gram-negativas. Deste modo, o objetivo do presente estudo foi testar a atividade repelente da peçonha de $D$. quadriceps na espécie de formiga cortadeira Atta sexdens Linnaeus, 1758, bem como, testar a ação antimicrobiana da peçonha de $D$. quadriceps em espécies de bactérias gram-positivas e gram-negativas. 


\section{MATERIAL E MÉTODOS}

Os espécimes de $D$. quadriceps foram capturados por meio da escavação dos ninhos e captura manual de todos os indivíduos encontrados, com auxílio de pinças entomológicas, em uma área urbanizada do município de Esplanada/BA (11ํ 47' 46" S 37ํ5' 42" W). Foram coletadas duas colônias: a primeira em 16 de junho de 2014 e a segunda em 02 de junho de 2015. Os indivíduos foram mantidos em ninhos artificiais de gesso, a temperatura ambiente, no Museu de Zoologia da Universidade do Estado da Bahia - UNEB, Campus II - Alagoinhas/BA. A dieta dos animais coletados foi baseada em artrópodes vivos (adultos de gafanhotos e baratas), coletados momentos antes da alimentação, em larvas de besouro (Tenebrio molitor Linnaeus, 1758) e mel. A alimentação era oferecida a cada dois dias, bem como água (em microtubos graduados de 1,5 $\mathrm{mL}$ ad libitum).

A extração da peçonha foi realizada utilizando-se duas diferentes técnicas, a primeira em microtubos graduados e a segunda em tubo capilar de vidro. Em ambas as técnicas, as formigas foram imobilizadas com pinça entomológica e estimuladas manualmente para liberação da peçonha.

$\mathrm{Na}$ primeira técnica com microtubo graduado (TM), cinco diferentes operárias de $D$. quadriceps foram utilizadas para a liberação da peçonha em um mesmo microtubo. A peçonha obtida foi diluída em $0,10 \mathrm{~mL}$ de água destilada e homogeneizada com agitador do tipo Vortex. Na segunda técnica com tubo capilar (TC), somente um indivíduo foi utilizado para obtenção da peçonha. O tubo capilar foi colocado em contato com água destilada e posteriormente a substância extraída foi impregnada em papel filtro.

Após a extração da peçonha foram realizados bioensaios para testar a atividade repelente da peçonha em operárias de $A$. sexdens. Os bioensaios foram realizados em béqueres de $500 \mathrm{~mL}$ de capacidade, onde o fundo foi coberto com um papel filtro sobre o qual foram desenhados três círculos concêntricos de 3, 2 e $1 \mathrm{~cm}$ de diâmetro, respectivamente, adaptado de Marlier et al. (2004).

As operárias de $A$. sexdens utilizadas nos testes de repelência foram coletadas diretamente do ninho e colocadas no béquer, 10 minutos antes de cada experimento, para exploração e reconhecimento do ambiente. Após esse período, um papel filtro limpo de $5 \times 5 \mathrm{~mm}$ foi preso ao centro do círculo interno, $1 \mathrm{~mm}$ acima do fundo do recipiente, e os comportamentos das formigas foram filmados (controle) por cinco minutos. Após esse tempo, o papel filtro foi substituído por outro de $5 \times 5 \mathrm{~mm}$ contendo a peçonha diluída, e os comportamentos das formigas foram novamente filmados por um período de cinco minutos. Esse experimento foi replicado 10 vezes para as duas metodologias.

Foi utilizada apenas uma operária de $A$. sexdens em cada bioensaio, as quais foram descartadas após a realização dos experimentos. Do mesmo modo, todos os papéis filtros utilizados foram trocados em cada uma das repetições. 
O comportamento das formigas foi analisado e classificado como repelente e não repelente (Tabela 1). Realizou-se o teste Z para comparação entre os dados, a partir do programa Statistica V.5.0 (Statsoft, 2005), a 95\% de confiança.

Para verificar se as amostras da peçonha homogeneizavam, foi feita a determinação da concentração de proteínas totais utilizando-se a metodologia proposta por Lowry et al. (1951), no Instituto de Ciências da Saúde (ICS) da Universidade Federal da Bahia (UFBA). Para isso, utilizouse $100 \mu \mathrm{L}$ de etanol, água destilada e fosfato salino (PBS). Foi utilizada a técnica de extração em microtubo graduado para cada um desses solventes. Para a dosagem da técnica de tubo capilar, a peçonha foi diluída somente em PBS.

Tabela 1. Comportamento de formigas submetidas a testes de repelência.

\begin{tabular}{ll}
\hline COMPORTAMENTO & DESCRIÇÃO \\
\hline NÃO REPELENTE & Toque com as antenas \\
1. Inspeção & Aproximação/Alimentação \\
2. Aceitação & Distância permanente sem contato prévio \\
3. Indiferença & \\
REPELENTE & Retirada rápida, esfregando as pernas e peças \\
4. Recuo & bucais no chão repetidamente; movimento de \\
& abertura e fechamento das mandíbulas \\
5. Evitação & Distância permanente após contato direto \\
6. Limpeza & Esfregação do corpo e das antenas uma na \\
& outra ou sobre a superfície. \\
\hline
\end{tabular}

A avaliação da ação antimicrobiana da peçonha $D$. quadriceps foi realizada com cepas padrão (American Type Collection Culture - ATCC) das bactérias gram-positivas Staphylococcus aureus Rosenbach, 1884, Micrococcus luteus Conh, 1872, Bacillus subtilis Conh, 1872 e das gramnegativas Escherichia coli Castellani e Chalmers, 1919 e Pseudomonas aeruginosa (Schroeter, 1872). A sensibilidade microbiana foi avaliada por meio do teste de disco-difusão (CLSI, 2005).

Foi testada a ação antibacteriana da peçonha de operárias de uma colônia mantida em condições de laboratório por um ano, e também, da peçonha de operárias de uma colônia que foi coletada no mesmo dia da realização dos testes. Foram realizadas três repetições para cada uma das cinco bactérias testadas.

As culturas bacterianas foram cultivadas a $37^{\circ} \mathrm{C}$ por 24 horas, em meio Ágar Nutriente. Para cada microrganismo foi utilizada uma placa de Petri, onde foram colocados cinco discos estéreis (6 mm de diâmetro), todos contendo $10 \mu \mathrm{L}$ da solução testada: 1) peçonha diluída em água destilada $\left(\mathrm{VH}_{2} \mathrm{O}\right)$; 2) Controle - impregnado de água destilada pura $\left(\mathrm{CH}_{2} \mathrm{O}\right)$; 3) peçonha diluída em etanol 
(VEtOH); 4) controle - impregnado de etanol puro (CETOL); e 5) controle positivo - DMSO (Dimetilsulfóxido) com cloranfenicol (0,1\%).

O inóculo foi transferido para a placa de Petri, com auxílio de um swab descartável e distribuído em toda a superfície de meio ágar nutriente. Em seguida foram colocados os discos com as substâncias testadas e o tratamento controle em cada placa de Petri. O sistema foi incubado a $37^{\circ} \mathrm{C}$, por 24 horas, em estufa bacteriológica. Após esse período, os resultados foram observados medindo-se a formação ou não do halo de inibição.

\section{RESULTADOS}

A determinação da concentração de proteínas totais revelou maior presença de proteínas nas amostras utilizando-se a solução tampão fosfato salino (PBS) como solvente, sendo também maior na amostra extraída com tubo capilar $(80 \mathrm{mg} / \mathrm{mL})$. A peçonha extraída desta forma ficou mais concentrada, pois a quantidade de solvente utilizado foi menor, permitindo detectar maior quantidade de proteínas. A amostra extraída em microtubo graduado foi de 2,0 mg/mL para o etanol, $6,0 \mathrm{mg} / \mathrm{mL}$ para água destilada e $20,0 \mathrm{mg} / \mathrm{mL}$ para PBS. O PBS é mais indicado como solvente, pois estabiliza as substâncias e mantém as suas propriedades.

Nos testes com microtubo graduado, foi possível verificar que as operárias de $A$. sexdens percorriam toda a área sem restrição, tanto no tratamento controle quanto no experimental. $O$ comportamento mais comum entre as operárias de $A$. sexdens foi indiferença, inspeção e aceitação (Tabela 2). Quando comparado com o controle, o comportamento de indiferença foi inferior e houve aceitação e inspeção. Não houve diferença significativa entre tratamento e controle, pelo teste $Z$. Mas as diferenças ficaram próximas da significância, o que pode indicar uma tendência à repelência. Além dos comportamentos já pré-determinados como não repelentes por Marlier et al. (2004), foram observados nesse estudo outros comportamentos das formigas-alvo que também podem evidenciar não repelência, como o de percorrer toda a área sem restrição ou permanecer imóvel em um mesmo local, sem reação ou movimento.

Nos testes com tubo capilar as trajetórias realizadas pelas formigas permaneceram quase sempre circulares.

De modo geral não houve diferença significativa no teste $Z$ e entre os comportamentos que indicam repelência e não repelência. Também não houve diferença entre os métodos de extração da peçonha, microtubo graduado e tubo capilar, de $D$. quadriceps pelo teste de Mann Whitney (Tabela 2). 
Tabela 2. Frequência absoluta dos comportamentos observados nas operárias de Atta sexdens quando expostas a peçonha de Dinoponera quadriceps extraída com microtubo graduado e tubo capilar de vidro $(n=10)$.

\begin{tabular}{ccccc}
\hline COMPORTAMENTO & CONTROLE & TESTE & CONTROLE & TESTE \\
OBSERVADO & TM (\%) & TM (\%) & TC (\%) & TC (\%) \\
\hline
\end{tabular}

NÃO REPELÊNCIA

$\begin{array}{lllll}\text { Inspeção } & 0 & 30 & 0 & 10 \\ \text { Aceitação } & 0 & 30 & 30 & 40 \\ \text { Indiferença } & 100 & 70 & 70 & 60 \\ \text { REPELÊNCIA } & & & & \\ \text { Recuo } & 0 & 0 & 0 & 0 \\ \text { Evitação } & 0 & 0 & 0 & 0 \\ \text { Limpeza } & 0 & 0 & 0 & 0\end{array}$

$\overline{\mathrm{TM}}=$ técnica de extração da peçonha em microtubo graduado; TC = técnica de extração da peçonha em tubo capilar de vidro; Não houve diferença significativa pelo teste $Z(p>0,05)$.

Com relação aos testes antimicrobianos da peçonha para as cinco linhagens de bactérias testadas, E. coli, P. aeruginosa, S. aureus, B. subtilis, e M. luteus, verificou-se halo de inibição apenas para $M$. luteus. Isso também ocorreu apenas em uma das repetições e com a peçonha extraída após o ninho artificial ter sido mantido por um ano em cativeiro. Para a peçonha de formigas extraídas no mesmo dia que as formigas foram coletadas, não houve halo de inibição.

Os testes antimicrobianos não apresentaram atividade com os solventes utilizados. Os resultados não mostraram nenhuma diferença quanto à ação bacteriana para a peçonha coletada de formigas mantidas por um ano em cativeiro e formigas coletadas no mesmo dia para as espécies testadas.

\section{DISCUSSÃO}

A peçonha de $D$. quadriceps cristaliza minutos após a extração, o que pode ter dificultado sua diluição com os solventes utilizados. Além disso, como na peçonha de outros insetos, deve possuir compostos de alta volatilidade que evaporam rapidamente (Bruschini et al., 2006). As condições de saúde das formigas e sua idade também influenciam a composição da peçonha (Johnson et al., 2010). Assim, a ação de fatores como baixa concentração da peçonha obtida, rápida cristalização, além da dificuldade de se extrair a peçonha, devido a agressividade das formigas, podem ter dificultado a obtenção de quantidade suficiente para a detecção de substâncias e sua sensibilização pelos indivíduos de $A$. sexdens, permitindo que eles percorressem toda a área sem restrição, com comportamentos não repelentes de aceitação ou indiferença.

As operárias de formigas cortadeiras conseguem perceber a fonte de odor a distâncias menores que $24 \mathrm{~cm}$, desta forma, só são capazes de discernir odores e distinguir substâncias químicas que sensibilizam os órgãos sensoriais, apenas quando estão próximas do local de 
liberação dos compostos voláteis (Littledyke e Cherrett, 1978). Apesar das espécies testadas serem mantidas em distanciamento favorável à percepção do odor da peçonha, no presente estudo, não ocorreu comportamento de repelência. No entanto, os resultados foram próximos da significância, o que demonstra uma possível tendência a ocorrência.

Apesar dos resultados obtidos no presente trabalho, há registros (dados não pubicados) de repelência por peçonha de $D$. quadriceps contra espécies de formigas hospitalares Paratrechina longicornis (Latreille, 1802) e Camponotus rufipes (Fabricius, 1775), evidenciado pelos comportamentos de recuo, evitação e limpeza. Principalmente, quando essas espécies-alvo entraram em contato como o 2-ácido butanoico, substância volátil isolada e identificada por cromatografia gasosa na peçonha de $D$. quadriceps. Esses resultados revelam a necessidade de maiores investigações.

Outros estudos com a peçonha de $D$. quadriceps indicam a existência de peptídeos antimicrobianos e seu potencial contra espécies de bactéria e fungos, com ação bacteriostática e bactericida contra três linhagens de S. aureus (Lima et al., 2014). Desta forma, indicando a necessidade de estudos que envolvam outras técnicas de extração que permitam obter uma maior quantidade de peçonha.

\section{CONSIDERAÇÕES FINAIS}

No presente estudo, não foram detectados comportamentos de repelência nas operárias de $A$. sexdens quando expostas a peçonha de $D$. quadriceps. Do mesmo modo, não houve atividade antimicrobiana da peçonha em relação às bactérias testadas.

No entanto, devido à importância da peçonha de formigas, futuros estudos envolvendo diferentes técnicas ou o aprimoramento das aqui testadas, provavelmente poderão permitir que a peçonha de $D$. quadriceps possa ser usada como repelente contra pragas de plantas cultivadas.

\section{AGRADECIMENTOS}

Agradecemos a Universidade do Estado da Bahia - Campus II, pela infraestrutura para realização da pesquisa. À Fundação de Amparo à Pesquisa do Estado da Bahia (FAPESB), pela concessão da bolsa de estudo de E. S. Araujo. Aos estagiários do Museu de Zoologia, Pedro Thiago Barreto de Sá, Jordana Gabriela Barreto de Sá, Thais dos Santos Rocha, Camila Machado do Nascimento e Danilo Abreu Reis, pelo auxílio na coleta das colônias. A Profa Dra Vera Lúcia Costa Vale, pelo auxílio na dosagem de proteínas. Aos estagiários do Laboratório de Microbiologia, Arielle Araujo Santos e Maiara Silva dos Santos, pelo auxílio nos testes de atividade antimicrobiana.

\section{REFERÊNCIAS}

Abdalla, F. C.; Cruz-Landim, C. Dufour glands in the hymenopterans (Apidae, Formicidae, Vespidae): a review. Revista Brasileira de Biologia, 61(1), 95-106, 2001. 
Arcuri, H. A.; Palma, M. S. Understanding the Structure, Activity and Inhibition of Chorismate Synthase from Mycobacterium tuberculosis. Current Medicinal Chemistry, 18(9), 1311-1317, 2011.

Brady, S. G.; Schultz, T. R.; Fisher, B. R.; Ward, P. S. Evaluating alternative hypotheses for the early evolution and diversification of ants. Proceedings of the National Academy of Sciences, 103(48), 18172-18177, 2006.

Bruschini, C.; Dani, F. R.; Pieraccini, G.; Guarna, F.; Turillazzi, S. Volatiles from the venom of five species of paper wasps (Polistes dominulus. P. gallicus. P. nimphus. P. sulcifer and P. olivaceus). Toxicon, 47(7), 812-825, 2006.

Charpin, D.; Birnbaum, J.; Vervloet, D. Epidemiology of Hymenoptera allergy. Clinical and Experimental Allergy, 24(11), 1010-1015,1994.

Cintra, P.; Bueno, F. C.; Bueno, O. C.; Malaspina, O.; Petacci, F.; Fernandes, J. B. Astilbe toxicity to leaf-cutting ant Atta sexdens rubropilosa (Hymenoptera: Formicidae). Sociobiology, 45(2), 347353, 2005.

Clinical Laboratory Standards Institut - CLSI. Padronização dos Testes de Sensibilidade a Antimicrobianos por Disco-difusão: Norma Aprovada - 8aㅡ ed. M2-A8, 23(1), 2005.

Della-Lucia, T. M. C.; Souza, D. J. Importância e história de vida das formigas-cortadeiras. In: DellaLucia, T. M. C (Orgs). Formigas-cortadeiras: da bioecologia ao manejo. Viçosa: Editora UFV, 2011, p.13-26.

Johnson, S. R.; Copello, J. A.; Evans, M. S.; Suare, A. V. A biochemical characterization of the major peptides from the venom of the giant neotropical hunting ant Dinoponera australis. Toxicon, 55(4), 702-710, 2010.

Lai, L.; Hua, K.; Wu, W. Intraspecific and interspecific aggressive interactions between two species of fire ants, Solenopsis geminata and S. invicta (Hymenoptera: Formicidae), in Taiwan. Journal of Asia-Pacific Entomology, 18(1), 93-98, 2015.

Lima, D. B.; Torres, A. F.; Mello, C.P.; Menezes, R. R.; Sampaio, T. L.; Canuto, J. A.; Silva, J. J.; Freire, V. N.; Quinet, Y. P.; Havt, A.; Monteiro, H. S.; Nogueira, N. A.; Martins, A. M. Antimicrobial effect of Dinoponera quadriceps (Hymenoptera: Formicidae) venom against Staphylococcus aureus strains. Journal of Applied Microbiology, 117(2), 390-396, 2014.

Littledyke, M.; Cherrett, J. M. Olfactory responses of the leaf-cutting ants Atta cephalotes (L.) and Acromyrmex octospinosus (Reich) (Hymenoptera: Formicidae) in the laboratory. Bulletin of Entomological Research, 68(2), 273-28, 1978.

Lowry, O. H.; Rosebrough, N. J.; Farr, A. L.; Randall, R. J. Protein measurement with the Folin phenol reagent. Journal of Biological Chemistry, 193(1), 265-275, 1951.

Marinho, C. G. S.; Della-Lucia, T. M. C.; Picanço, M. C. Fatores que dificultam o controle das formigas cortadeiras. Bahia Agrícola, 7(2), 18-21, 2006.

Marlier, J. F., Quinet, Y.; Biseau, J. C. Defensive behaviour and biological activities of the abdominal secretion in the ant Crematogas terscutellaris (Hymenoptera: Myrmicinae). Behavioural Processes, 67(3), 427-440, 2004.

Oliveira, M. F. S. S.; Bueno, O. C.; Marini, T.; Reiss, I. C.; Bueno, F. C. Toxicity of Azadirachta indica to leaf-cutting ant Atta sexdens rubropilosa (Hymenoptera: Formicidae). Sociobiology, 47(2), 423431, 2006.

Orivel, J.; Redeker, V.; Le Caer, J. P.; Krier, F.; RevoL-Junelles, A. M.; Longeon, A.; Chaffotte, A.; Dejean, A.; Rossier, J. Ponericins, New Antibacterial and Insecticidal Peptides from the Venom of the Ant Pachycondyla goeldii. Journal Biological Chemistry, 276(21), 17823-17829, 2001. 
Saidemberg, D. M.; Passarelli, A. W.; Rodrigues, A. V.; Basso, L. A.; Santos, D. S.; Palma, M. S. Shikimate Kinase (EC 2.7.1.71) from Mycobacterium tuberculosis: Kinetics and Structural Dynamics of a Potential Molecular Target for Drug Development. Current Medicinal Chemistry, 18(9), 12991310, 2011.

Santos, L. D.; Pieroni, M.; Menegasso, A. R. S.; Pinto, J. R. A. S.; Palma, M. S. A new scenario of bioprospecting of Hymenoptera venoms through proteomic approach. Journal of Venomous Animals and Toxins including Tropical Diseases, 17(4), 364-377, 2011.

Schmidt, J. O. Chemistry, Pharmacology, and Chemical Ecology of Ant Venoms. In: PIEK, T. (Eds.) Venoms of the Hymenoptera: Biochemical, Pharmacological and Behavioural Aspects. Academic Press, Londres, 570 p., 1986.

Souza, P. L.; Quinet, Y.; Vale, J. F.; Torres, A. F. C.; Pereira, M. G; Assreuy, A. M. S. Venom's antinociceptive property in the primitive ant Dinoponera quadriceps. Journal of Ethnopharmacology, 144(1), 213-221, 2012.

Statsoft Inc. Statistica for Windows (data analysis software system), version 7.1. Statsoft, Tulsa, Oklahoma (USA), 2005.

Steen, C. J.; Janniger, C. K.; Schutzer, S. E.; Schwartz, R. A. Insect sting reactions to bees, wasps, and ants. International Journal of Dermatology, 44(2), 91-94, 2005.

Vaso, A. S.; Santos, D. S.; Basso, L. A.; Palma, M. S. Hydrogen/deuterium exchange mass spectrometry for characterizing phosphoenolpyruvate-induced structural transitions in Mycobacterium tuberculosis 5-enolpyruvylshikimate-3-phosphate synthase (EC 2.5.1.1). International journal of mass spectrometry, 302(3), 12-18, 2011.

Viegas, J. R.; Bolzani, C.; Silva, V.; Barreiro, E. J. Os produtos naturais e a medicina medicinal moderna. Química Nova, São Paulo, 29(2), 326-337, 2006. 